\title{
Arsenic Formation on GaAs during Etching in HF Solutions: Relevance for the Epitaxial Lift-Off Process
}

\author{
N. J. Smeenk, ${ }^{\text {a,z }}$ J. Engel, ${ }^{\text {a }}$ P. Mulder, ${ }^{\text {a }}$ G. J. Bauhuis, ${ }^{\text {a }}$ G. M. M. W. Bissels, ${ }^{\text {a J. J. Schermer, }}{ }^{\text {a }}$ \\ E. Vlieg, a and J. J. Kelly ${ }^{\text {,* }}$
}

${ }^{a}$ Institute for Molecules and Materials, Radboud University Nijmegen, 6525 AJ Nijmegen, The Netherlands

${ }^{b}$ Condensed Matter and Interfaces, Debye Institute for Nanomaterials Science, Utrecht University, 3508 TA Utrecht,

The Netherlands

\begin{abstract}
The epitaxial lift-off (ELO) process is utilized to produce thin-film III-V devices, while the substrate (GaAs wafer) on which the III-V structure was grown can be reused. However, so far the direct reuse of these GaAs wafers is inhibited by the remnants on the wafer surface that cannot be removed in a straightforward fashion utilizing general cleaning methods. Therefore, etching of GaAs wafers in hydrofluoric acid was investigated by microscopic techniques, profilometry and X-ray photoelectron spectroscopy. It was found that immediately after etching the wafer surface is covered by a brown layer of elemental arsenic. The thickness and uniformity of this layer depend on both illumination during etching and the HF concentration. During storage of the etched wafer the As layer is replaced by $\mathrm{As}_{2} \mathrm{O}_{3}$ particles. It is shown that oxide particles form only when the wafer is exposed to light in the presence of air. A model that explains the As formation and the subsequent particle formation is given.

(c) 2012 The Electrochemical Society. [DOI: 10.1149/2.006303jss] All rights reserved.
\end{abstract}

Manuscript submitted October 22, 2012; revised manuscript received December 4, 2012. Published December 19, 2012.

III-V solar cell technology is important in space and concentrated photovoltaic (CPV) applications. ${ }^{1}$ From a fundamental point of view III-V semiconductors are ideal for solar cell applications. A large range of III-V materials are direct semiconductors allowing for thinfilm cell structures, and III-V compounds can easily be combined into multi-junction cells yielding record efficiencies. ${ }^{2}$ Present commercially available triple-junction cells for CPV systems reach efficiencies as high as $38 \%$, while current research is aiming to demonstrate efficiencies above $50 \%$.

A major disadvantage in the production of high-efficiency III-V solar cells is that they require an expensive single-crystalline GaAs or Ge wafer as a template. After deposition of the solar cell structure the wafer is of no further use for its performance. Nevertheless, using the present fabrication techniques the active thin-film structure including the passive wafer are processed together to a thick solar cell. In order to avoid wasting the substrate, our research group has perfected an epitaxial lift-off (ELO) technique to separate thin-film solar cells from their wafer and transfer them to an inexpensive carrier. The ELO process involves the selective etching of an intermediate AlAs release layer, resulting in thin film cell structures and thus allowing reuse of the wafer. Over the years this research has yielded significant increases in etch rate,,$^{3,4}$ an increase in sample size up to 4 inch wafers, ${ }^{4-6}$ thin-film GaAs cells with record efficiencies $(26.1 \%),{ }^{7}$ and the demonstration of its potential for space applications. ${ }^{8}$ In recent years the importance of the ELO technology for PV applications has received wide-spread attention, resulting in further increase of the thin-film GaAs cell efficiency to $28.3 \%{ }^{9}$ and industrial interest for genuine thin-film cell production. ${ }^{10-14}$

The aim of ELO is to allow the reuse of the wafer for the production of a large number of thin-film cells with a minimum of wafer repreparation between consecutive deposition runs. It has been demonstrated that chemo-mechanical polishing of the wafers results in a series of consecutive thin-film solar cells without any reduction in cell performance. ${ }^{6}$ However, chemo-mechanical polishing is a rather cumbersome process that reduces the wafer thickness by about $10 \mu \mathrm{m}$ each time, thus decreasing the cost benefit while limiting the number of wafer reuse cycles to 10 to 20 .

Therefore, the use of a simple wet-etch procedure to clean the wafer after ELO is highly desirable. However, initial investigations showed that such procedures result in a serious deterioration of the performance of cells obtained from reused wafers, even when the wafers appeared clean and smooth to the naked eye after etching. ${ }^{6}$ Several studies were conducted to identify the actual residue that

\footnotetext{
*Electrochemical Society Active Member.
}

${ }^{\text {z} E-m a i l: ~ n . s m e e n k @ s c i e n c e . r u . n l ~}$ must be removed by the wafer re-preparation process. ${ }^{15,16}$ Because of the high etch selectivity of a HF solution for AlAs with respect to GaAs $\left(\sim 10^{6}\right)^{17,18}$ it was assumed that the residue only originated from the AlAs release layer. However, we recently observed that etching of GaAs wafers in a HF solution results in a surface with a brown haze similar to that observed on a wafer after ELO etching of the thin film structure. This observation indicates that the residue after ELO (at least partly) results from etching of the GaAs wafer and not only from etching of the sacrificial release layer. In the present study the mechanism of formation of the brown layer upon GaAs etching in a HF solution and subsequent evolution of the deposit during storage are studied in detail.

\section{Experimental}

All experiments were performed on $1 \times 1 \mathrm{~cm}^{2} \mathrm{n}$-type GaAs samples, all samples were prepared from new (100) GaAs wafers. A corner of each sample was covered with photoresist to prevent etching at that location. After removal of the photoresist the etch rate could be determined by measuring the step height between the masked corner and the etched part of the sample. All experiments were performed by placing a GaAs sample face up in a vessel and adding $6 \mathrm{~mL}$ of a HF solution in water, from a stock solution. Typically, a $20 \% \mathrm{HF}$ concentration was used, unless otherwise specified. The etchant was used at room temperature (approximately $21^{\circ} \mathrm{C}$ ) and was not stirred during the experiments. After the designated etch time, samples were removed and rinsed in deionized water. All etching experiments were performed in triplicate. The uniformity of the deposit was observed initially by the naked eye. To determine the etch rate and the thickness of the brown deposit that appears during etching, the step height was measured using a Veeco Dektak 6M stylus profiler. The deposit thickness was measured by removing the brown layer at three places on the sample with a cotton tip, immediately after rinsing the sample. Since this thickness is measured with the profiler, it is an average value over several hundred microns.

After etching, the samples were stored for different periods of time under ambient conditions (i.e. while exposed to light and air, and at room temperature), except for a few storage experiments where samples were kept under oxygen-free conditions $\left(\mathrm{N}_{2}\right.$ purged atmosphere, oxygen concentration $<5 \mathrm{ppm}$ ) and/or in the dark. Illumination was provided by ambient light (fluorescent lamps), which on a GaAs photodiode generates a short-circuit current density of $0.09 \mathrm{~mA} / \mathrm{cm}^{2}$. The formation of particles during storage of previously etched samples was studied by scanning electron microscopy (SEM) and optical microscopy. A JEOL JSM 6330F was used for the SEM images, and for optical microscopy a Reichert-Jung Polyvar equipped with a Leica 


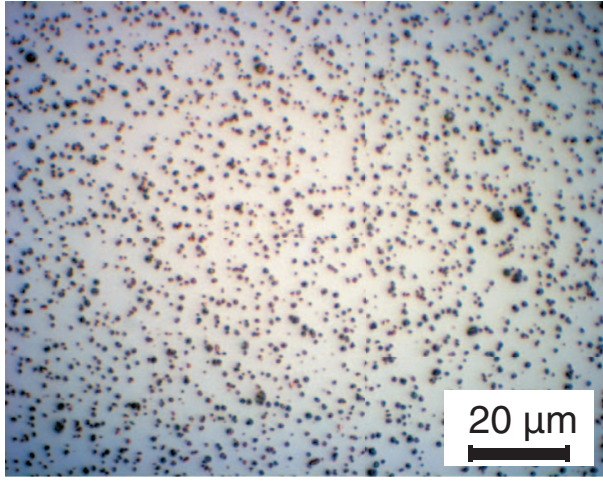

(a)

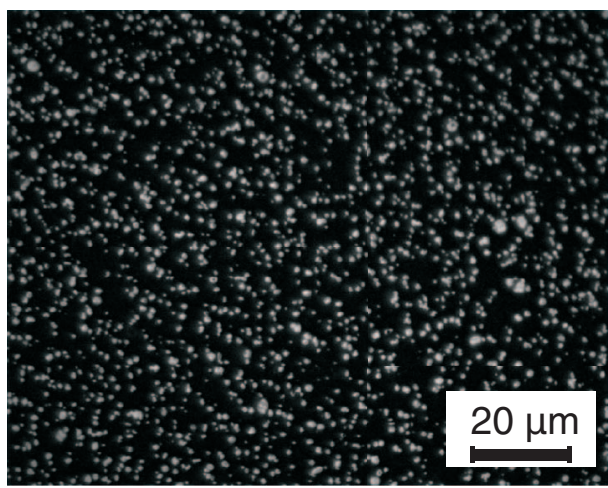

(b)

Figure 1. Optical micrograph of (a) the particles found on an etched and stored sample, and (b) after the corrected background intensity was subtracted from the image intensity (using an inverted greyscale).

CCD camera in differential interference contrast microscopy (DICM) mode was used. Samples were subjected to atomic force microscopy (AFM) analyzes using a Digital Instruments Nanoscope 3100 in contact mode with a $\mathrm{Si}_{3} \mathrm{~N}_{4}$ tip.

$\mathrm{X}$-ray photoelectron spectroscopy (XPS) measurements were performed at the $\mathrm{MESA}^{+}$Nanolab in Enschede, using a Quantera SXM with a base pressure $<10^{-8}$ torr and an $\mathrm{Al} \mathrm{K} \alpha$ monochromatic X-ray source. The measurements were carried out with an electron take-off angle of $45^{\circ}$, unless otherwise specified. With a take-off angle of $45^{\circ}$ and the X-ray source used, one detects photoelectrons that originate from within the top $10 \mathrm{~nm}$ of the sample. During transportation to the XPS facility the samples were kept in vacuum and in the dark to avoid contamination and oxidation.

The optical micrographs were analyzed for particle formation using a MatLab algorithm. The straightforward method of segmentation is to convert the image to grayscale, and subsequently separate the particles from the background by the difference in intensity (gray value). However, this does not take into account the non-uniformity of the background, for example as shown in Figure 1a, where the background at the center is brighter than at the edges of the image.

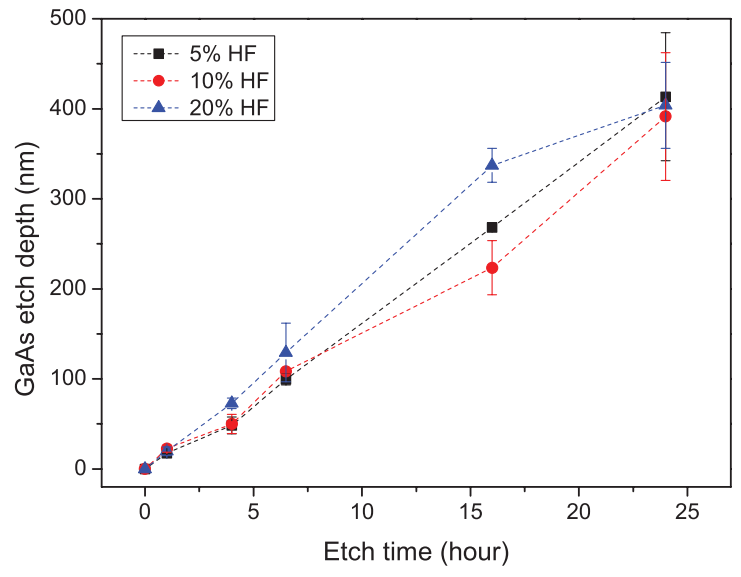

Figure 3. GaAs etch depth as a function of the etch time for three HF concentrations. Dotted lines are to guide the eye.

This non-uniformity can give the background in the corners the same gray value as particles in the center of the micrograph. Therefore, the MatLab algorithm ${ }^{19}$ first corrects for the background and then performs the segmentation using a watershed algorithm. In this way the microscope pictures could be analyzed and parameters such as particle density and percentage of particle-covered area could be determined conveniently. In this study we will use the percentage of the surface covered by particles (i.e. the number of particle pixels divided by the total number of pixels) to categorize the samples. This is done because typically a distribution of particle sizes was observed for different samples etched under identical conditions, resulting in a significant difference in the number of particles, while the area covered was approximately the same.

\section{Results}

In a first series of experiments samples were etched either in the dark or exposed to ambient light. The etch rate was comparable for all the samples, but significant differences in the brown deposit that formed on the etched surface were observed. During etching under illumination, a thin, uniform layer was formed, while etching in the dark resulted in a thicker, non-uniform deposit with some (almost) bare areas on the surface (see Figure 2). SEM analysis shows that the surface of the brown deposit consists of small hillocks.

Considering the illumination conditions during the ELO process (ambient light), all subsequent samples were exposed to light during etching. The samples were etched for various times in solutions with different HF concentrations to study the etch rate and deposit layer thickness. Storage conditions (illumination and exposure to air) were varied to determine the effect of these factors on the particle formation.

In Figures 3 and 4 the GaAs etch depth and deposit thickness after etching are shown as a function of etching time for three HF concentrations. The data points in these figures are for different GaAs samples, i.e. samples taken out of the etchant were not re-immersed for further etching. It can be seen that the GaAs etch depth increases

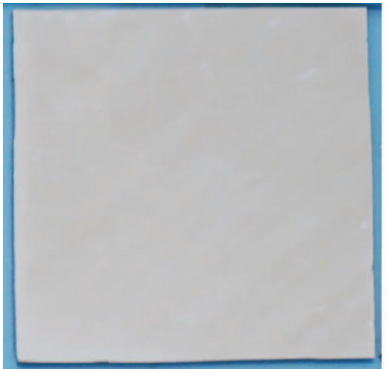

(a)

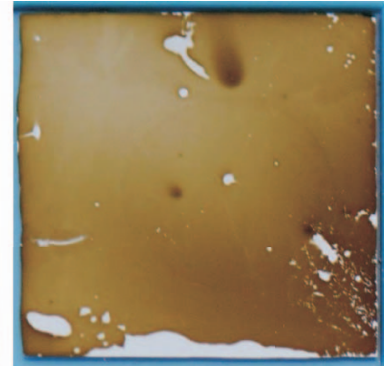

(b)

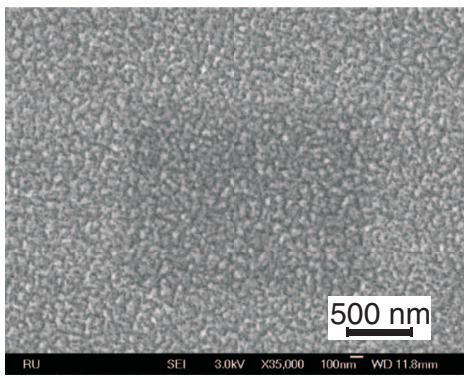

(c)
Figure 2. Photographs of the brown deposit that forms on $1 \times 1 \mathrm{~cm}^{2} \mathrm{GaAs}$ samples that were a) exposed to ambient light and b) kept in the dark during etching; c) SEM micrograph showing the hillocks on the brown deposit. 


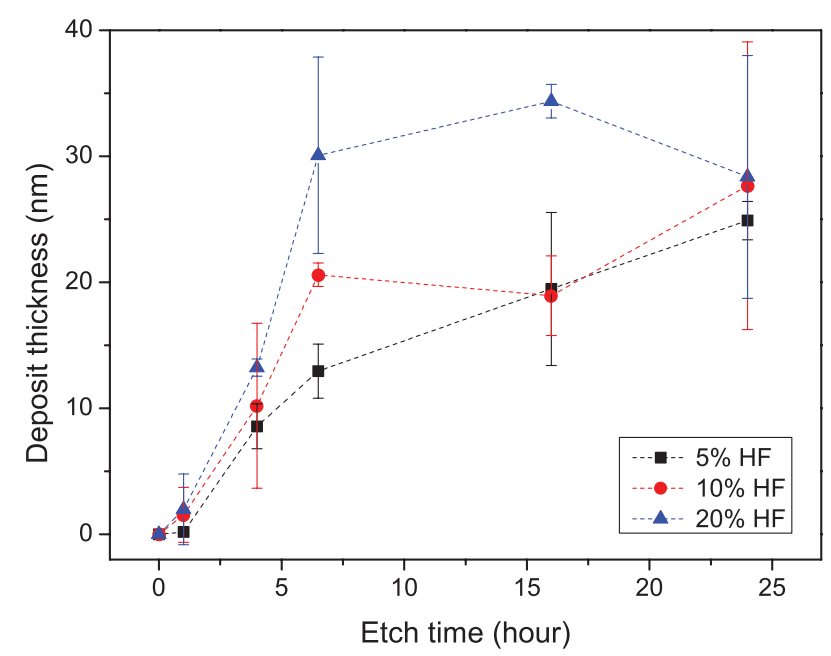

Figure 4. Deposit thickness after etching as a function of the etch time for three HF concentrations.

linearly in time, indicating a constant etch rate of about $16 \mathrm{~nm} / \mathrm{hour}$. Only a weak relationship between the etch rate and the HF concentration in the etchant is observed. The thickness of the brown deposit increases in time, but tends to a constant value in the range of $20-30 \mathrm{~nm}$ after approximately 7 hours of etching. A higher HF concentration results in a thicker deposit layer, although data points from different samples etched under the same conditions sometimes showed a large variation.

It was found that during storage of etched samples in ambient conditions the brown deposit gradually disappeared and was replaced by a gray haze on the surface. DICM inspection revealed that this gray haze consists of particles (see Figure 1) that had formed on the etched surface, previously covered by the brown deposit. Figure 5 shows the particle area coverage after 24 hours of storage, which is expected to correlate with the deposit thickness since particles only form on areas that were covered by the brown deposit. The particle area coverage also reaches a constant value after prolonged etching times. The correlation between HF concentration and particle area is more obvious: a higher concentration results in a larger surface coverage.

Figure 6 shows SEM images of GaAs samples (a) taken directly after etching (when the brown deposit covers the surface), (b) after 3 hours and (c) 4 weeks of storage of the etched sample. Immediately

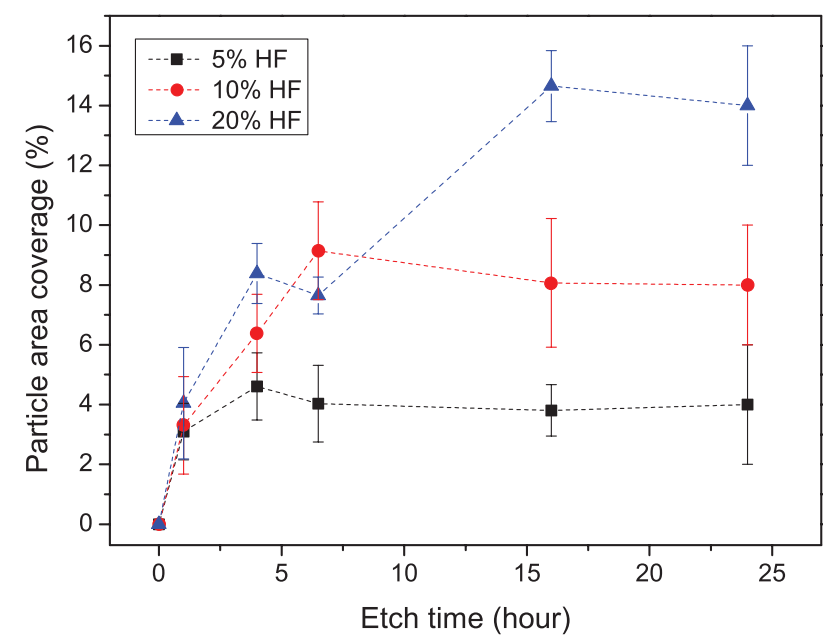

Figure 5. Particle area coverage as a function of the etch time for three HF concentrations as determined after 24 hours of storage.

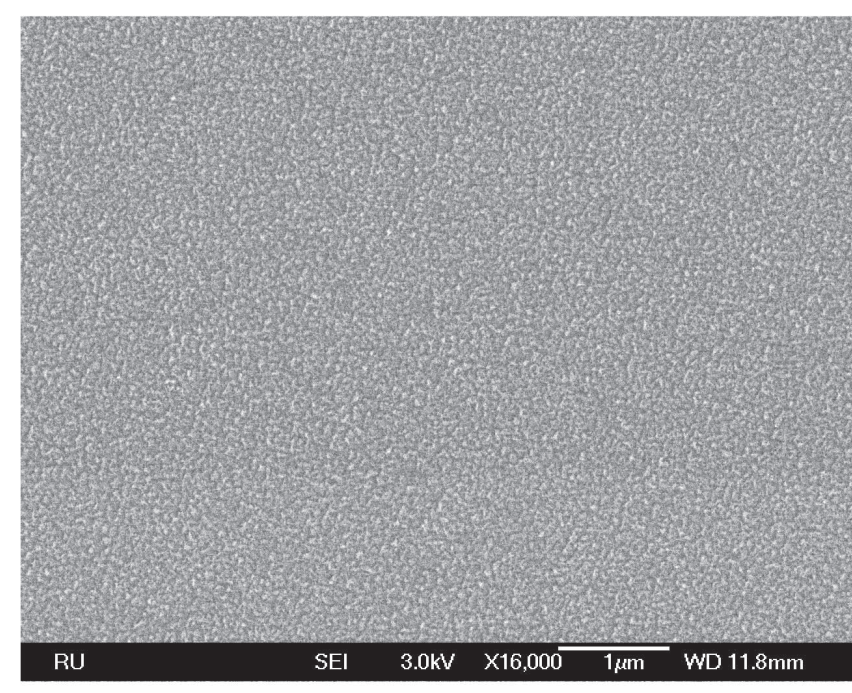

(a)

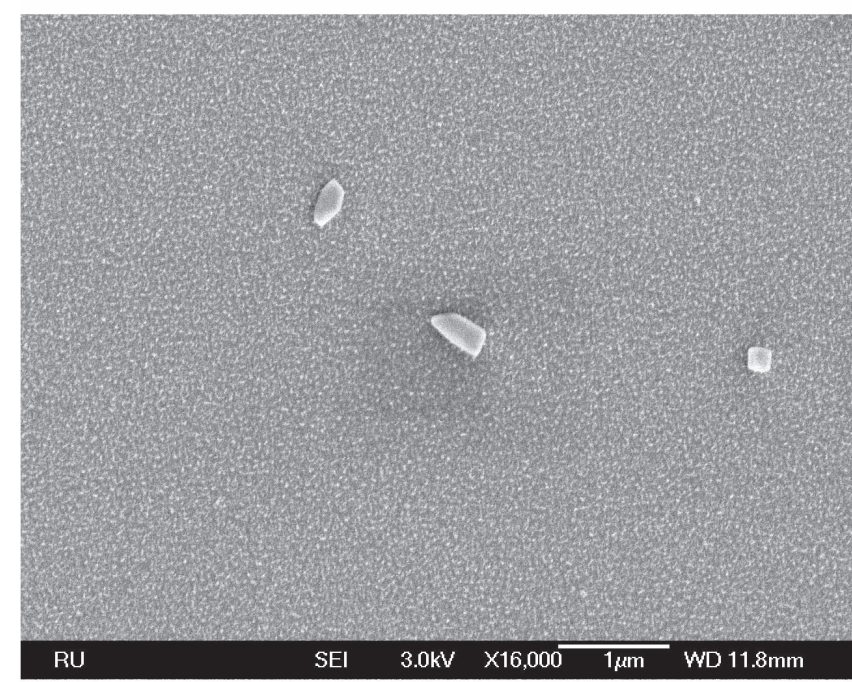

(b)

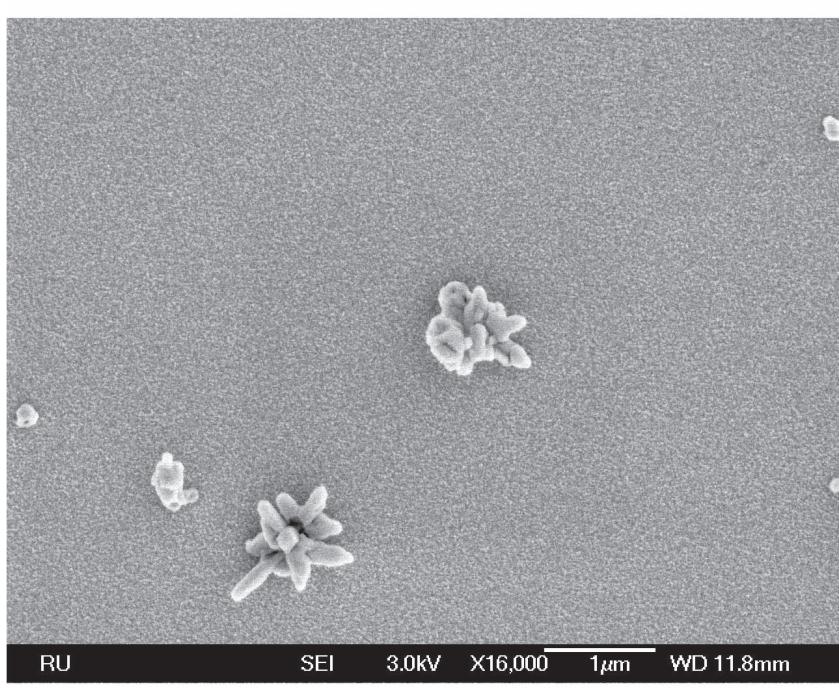

(c)

Figure 6. SEM images of GaAs samples a) directly after etching, b) after storage of the etched sample for 3 hours, and c) for 4 weeks. 


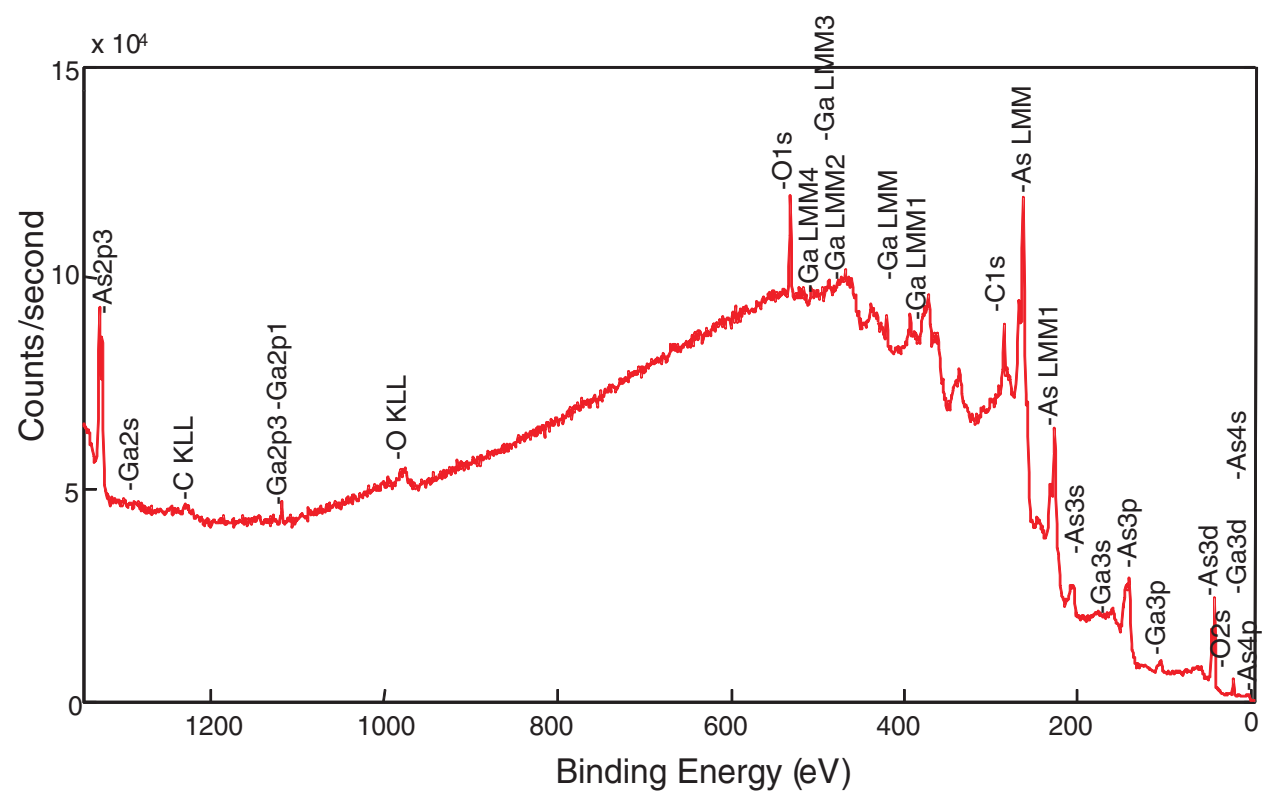

Figure 7. Typical XPS survey scan of a GaAs sample etched for 24 hours and stored for 4 hours, showing that only the elements As, Ga, C and $\mathrm{O}$ are present in detectable quantities.

after etching the surface is covered by small hillocks $(<100 \mathrm{~nm})$. After storage micro-crystals are observed on the sample surface, while AFM analysis shows that the roughness of the sample surface in between the crystals decreases significantly. This suggests that the hillocks are due to the initial brown deposit that gives rise to micro-crystals during storage. These micro-crystals can have a size up to a few microns, confirming that these are the particles seen in the DICM images (see Figure 1a).

In order to determine the composition of the initial deposit and that of the micro-crystals, XPS measurements were performed on four samples: a non-etched new wafer, a sample directly after etching and two etched and stored samples, one stored for 4 hours, the other for 4 weeks. A survey scan of an XPS measurement on a sample stored for 4 hours is shown in Figure 7. All samples gave similar survey scans, only the peak intensities differed. The scan shows that the only elements present on the sample in detectable quantities were As, $\mathrm{Ga}, \mathrm{O}$ and $\mathrm{C}$. The carbon signal is due to exposure of the samples to the ambient environment, resulting in hydrocarbon deposition on the surface. This adventitious carbon layer, with a C-1s peak at $284.8 \mathrm{eV}$, was used as a binding energy reference. ${ }^{20}$ No fluoridecontaining compounds were detected, indicating that such etch reaction products, if formed, dissolve in the etchant.

High resolution spectra of the As-3d and Ga-3d peaks were recorded (see Figure 8), in order to determine the oxidation state and chemical environment of As and Ga. For the new sample clearly most of the As and Ga signals can be attributed to GaAs and to some oxide that is present on new wafers. XPS measurements of the etched samples show that directly after etching, when the surface is covered by the brown deposit, most of the As signal is due to elemental arsenic; there is a small signal related to $\mathrm{As}_{2} \mathrm{O}_{3}$, but no signal related to GaAs. Neither is such a signal present in the Ga-3d peak at that stage, in fact the Ga signal has completely disappeared, indicating that Ga compounds are not present at the surface of the etched sample. During storage, the elemental arsenic peak decreases and the $\mathrm{As}_{2} \mathrm{O}_{3}$ peak increases. After 4 weeks of storage a small amount of $\mathrm{As}_{2} \mathrm{O}_{5}$ seems to be present. The Ga signal re-appears during storage, coming first only from GaAs; upon prolonged storage the presence of $\mathrm{Ga}_{2} \mathrm{O}_{3}$ is also observed. The re-appearance of the $\mathrm{Ga}$ signal indicates a decrease in the thickness of the elemental arsenic layer during storage.

The storage of etched samples so far was carried out in air and ambient light. Since illumination during etching influences the formation of the brown deposit, we investigated whether this was also the case for the micro-crystal formation during storage of the etched samples. Etched samples were illuminated in air immediately after etching and after 23 and 47 hours of storage, and the particle area was determined. This showed that particles only form when the sample was exposed to light during storage; when a sample was stored in the dark the brown deposit was not converted into micro-crystals. Samples that were first stored in the dark (e.g. for 23 hours) showed particle formation after subsequent exposure to light.

Oxygen was also found to be important. No micro-crystal formation was observed during storage in a nitrogen-purged atmosphere under illumination. However, particle formation was initiated once the samples were exposed to air.

The role of air in the particle formation implies that the microcrystals are the product of an oxidation reaction. This was confirmed by XPS measurements performed on an etched sample that was stored under ambient conditions (i.e. exposed to light and oxygen) for 4 hours, so that particles had started to form. A series of spectra were obtained in which the electron take-off angle with respect to the sample surface was lowered from $45^{\circ}$ to $10^{\circ}$ and $5^{\circ}$, so that the measurements became more surface sensitive and thus gave a larger contribution of the micro-crystals to the XPS signal. These XPS spectra (Figure 9) show that upon lowering the take-off angle the $\mathrm{As}_{2} \mathrm{O}_{3}$ signal increases with respect to that of the elemental As signal, while the Ga signal disappears entirely (since no Ga signal was present at a $10^{\circ}$ take-off angle, no measurement on $\mathrm{Ga}$ was recorded at a $5^{\circ}$ take-off angle).

\section{Discussion}

A brown deposit is formed on the surface of GaAs samples etched in concentrated HF solutions. Niftrik et al. ${ }^{15}$ reported that during etching of the AlAs release layer in an ELO geometry in the same solution a brown deposit is formed on the adjacent GaAs-substrate and thin-film surfaces. The hillocks they observed on the GaAs surface were similar in size and shape to those found in the present work. As in the ELO case, the deposit could be easily removed by a cotton tip. Our XPS measurements show that the layer consists of elemental arsenic and no fluoride-containing products were detected. This is in agreement with work of Storm et al. ${ }^{21}$ who have shown that fluoride compounds are only observed by XPS for etching times of less than 

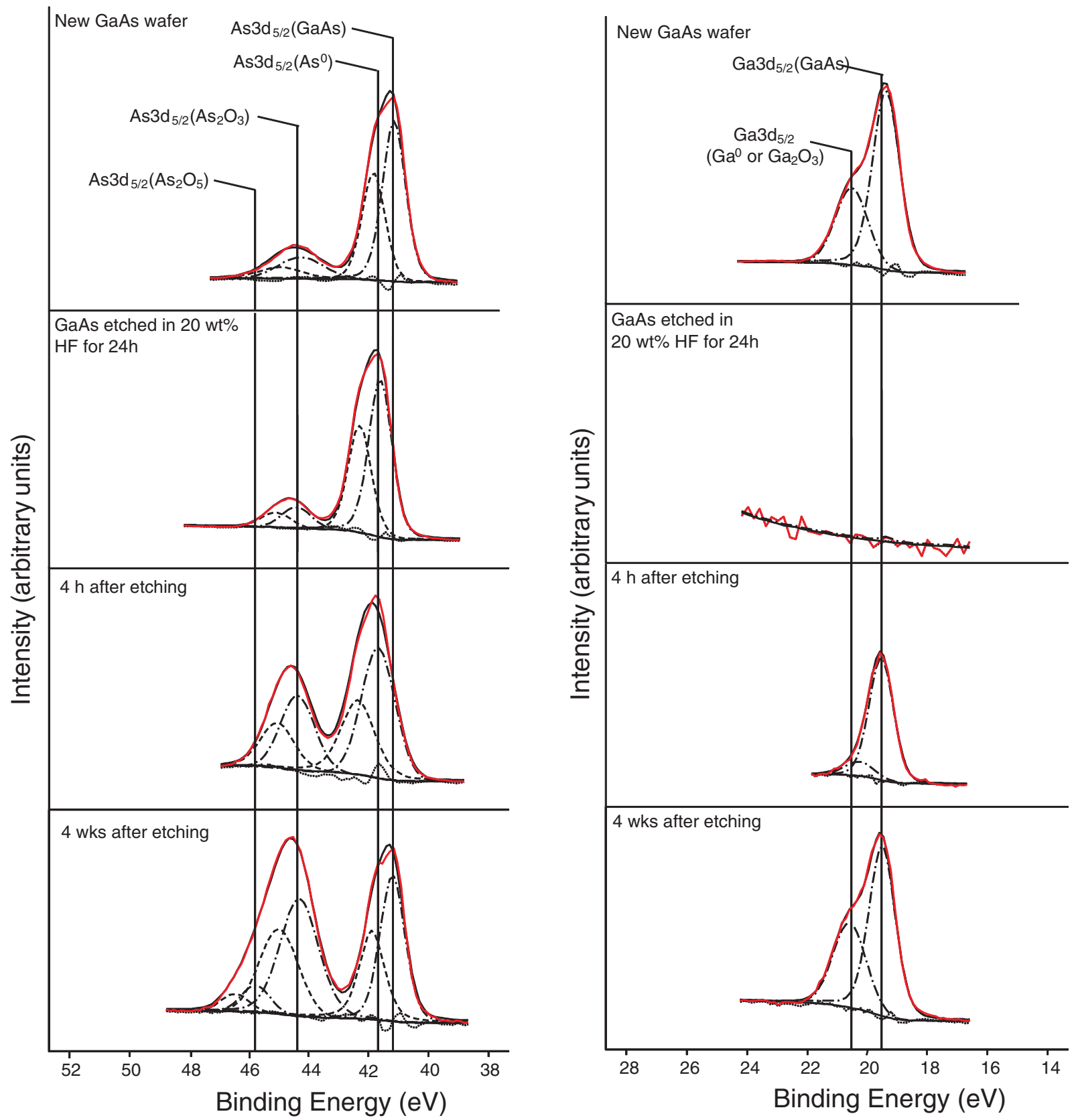

Figure 8. High resolution XPS spectra (the vertical scale is linear) of the As-3d peak (left) and the Ga-3d peak (right). The measured samples are (top to bottom): a new GaAs wafer, a sample directly after etching, and two samples stored after etching for 4 hours and 4 weeks, respectively. The red lines are the measured curves, the black are calculated peak-fits.

about 10 minutes. In order to facilitate the discussion below on the formation mechanisms of $\mathrm{As}$ and $\mathrm{As}_{2} \mathrm{O}_{3}$, Figure 10 gives a schematic overview.

In the dark GaAs is very likely etched chemically by undissociated $\mathrm{HF}$ (or $\mathrm{HF}_{2}{ }^{-}$) via a synchronous bond-exchange mechanism: ${ }^{22} \mathrm{Ga}-\mathrm{As}$ and $\mathrm{H}-\mathrm{F}$ bonds are broken and $\mathrm{Ga}-\mathrm{F}$ and $\mathrm{As}-\mathrm{H}$ bonds are formed.

$$
\mathrm{GaAs}+3 \mathrm{HF} \rightarrow \mathrm{GaF}_{3}+\mathrm{AsH}_{3}
$$

The Ga product dissolves as a fluoride or aqua-fluoride complex and arsine $\left(\mathrm{AsH}_{3}\right)$ is formed. ${ }^{15}$ This mechanism is similar to that responsible for the etching of $\mathrm{InP}$ by undissociated $\mathrm{HCl}$ in acetic acid or concentrated aqueous solutions, ${ }^{23}$ in which phosphine $\left(\mathrm{PH}_{3}\right)$ gas is formed. Niftrik et al. ${ }^{15}$ used a similar mechanism to explain the etching of AlAs in a HF solution; in that case the formation of $\mathrm{AsH}_{3}$ was detected during the experiments. The arsine, formed in reaction 1 , can give rise to elemental arsenic.

$$
2 \mathrm{AsH}_{3} \rightarrow 2 \mathrm{As}+3 \mathrm{H}_{2}
$$

This could occur directly by chemical decomposition or via a redox reaction involving protons. Since the As layer on the surface does not hinder the etching reaction (see Figure 3 ) it is likely to have an open or porous structure.

After 24 hours of etching a layer of GaAs typically $400 \mathrm{~nm}$ thick is removed while only a $20-30 \mathrm{~nm}$ layer of As is grown (Figures 3 and 4). It is unlikely that all the $\mathrm{AsH}_{3}$ formed will be converted to As; the hydride can escape and react with oxygen in solution or in air. Arsenic may itself be oxidized by oxygen to give arsenates, which are soluble in acidic solutions.

The As layer formed during etching under illumination is uniform, and its thickness is less than the maximum thickness of the darketched samples. These results suggest that light plays a role in As 

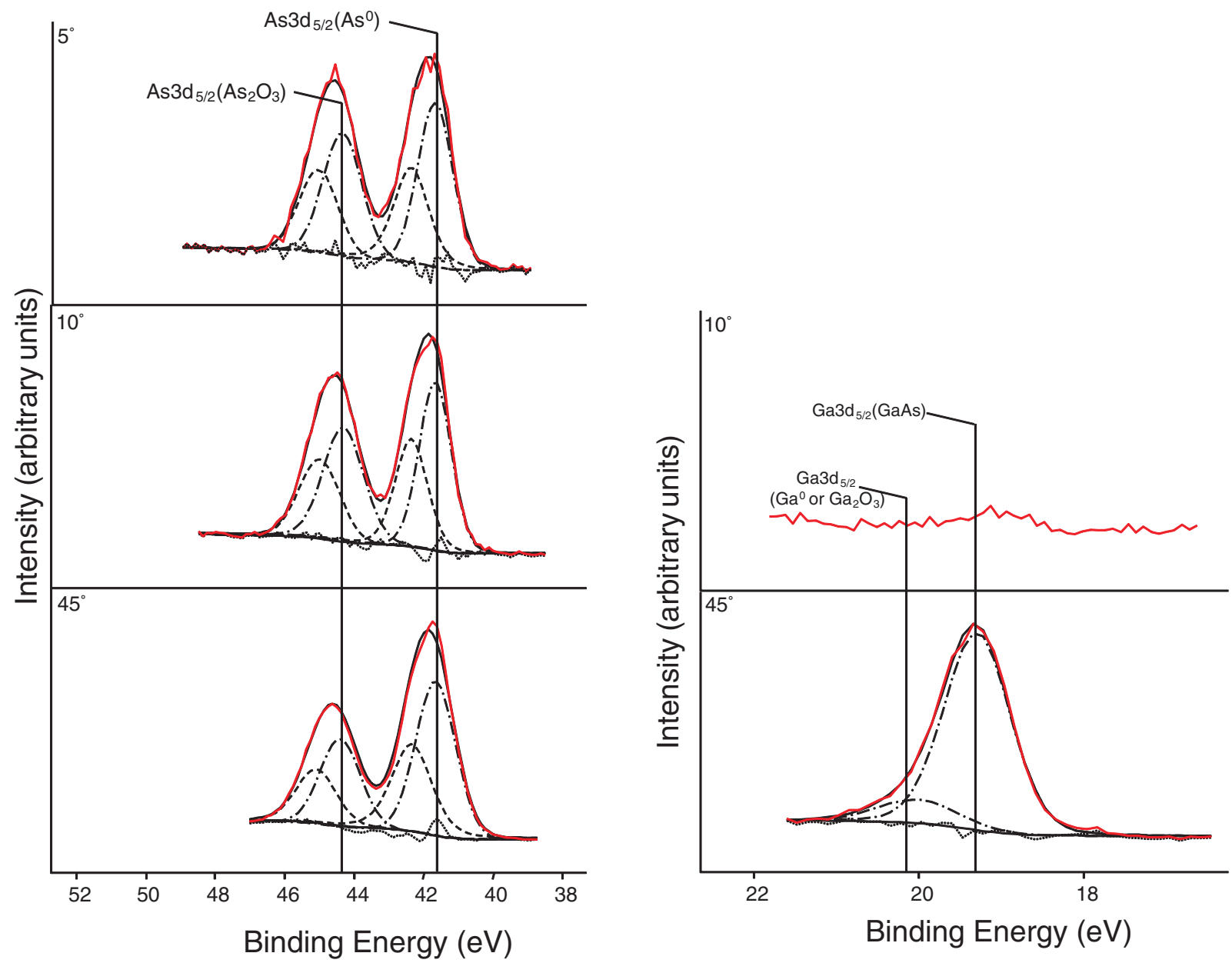

Figure 9. High resolution XPS spectra (the vertical scale is linear) of the As-3d (left) and Ga-3d (right) signals with varying electron take-off angles. These take-off angles are $5^{\circ}$ (top, only measured for As), $10^{\circ}$ (middle) and $45^{\circ}$ (bottom).

formation during etching. In a study of "rolled-up nanotech" based on ELO with an AlAs sacrificial layer, Costescu et al. ${ }^{24}$ reported a marked influence of illumination on the etching result in HF solutions. When a semiconductor in solution is exposed to supra-bandgap light, electroless photoetching can occur. ${ }^{22,25}$ The electrons, generated by light, reduce an oxidizing agent in solution; the holes are used to oxidize the semiconductor. In the case of a III-V material the latter reaction usually takes one of two forms: a six-hole process in which both the group III and V elements are oxidized to the trivalent state or a three-hole process in which only the group III element is oxidized. ${ }^{23,26,27}$ For GaAs in acidic solutions these reactions can be represented by:

$$
\begin{gathered}
\mathrm{GaAs}+2 \mathrm{H}_{2} \mathrm{O}+6 \mathrm{~h}^{+} \rightarrow \mathrm{Ga}^{3+}+\mathrm{HAsO}_{2}+3 \mathrm{H}^{+} \\
\mathrm{GaAs}+3 \mathrm{~h}^{+} \rightarrow \mathrm{Ga}^{3+}+\mathrm{As}
\end{gathered}
$$

In a HF solution the $\mathrm{Ga}^{3+}$ ions will be complexed. The photogenerated electrons can reduce oxygen, ${ }^{28}$ usually present in an aqueous solution.

$$
\mathrm{O}_{2}+4 \mathrm{H}^{+}+4 \mathrm{e}^{-} \rightarrow 2 \mathrm{H}_{2} \mathrm{O}
$$

In electroless photoetching the rates of the electron and hole reactions are equal. These reactions must compete with electron-hole recombination. Since light has no observable influence on the total etch rate, the rates of reactions 3 and 4 must be considerably lower than the rate of reaction 1 .
The non-uniformity of the arsenic layer formed from $\mathrm{AsH}_{3}$ decomposition during etching of GaAs in the dark (reaction 2) is very likely due to the difficulty of nucleating the film. Arsenic formed directly in reaction 4 can provide nuclei for further growth via reaction 2 . In this way uniform deposition is ensured, as observed during etching under illumination.

The fact that formation of $\mathrm{As}_{2} \mathrm{O}_{3}$ from As on stored samples of etched GaAs requires both air and light suggests a photocatalyzed reaction. A possible mechanism would involve the photoexcitation of GaAs (arsenic, being a semi-metal, is unlikely to be photoactive). Photogenerated electrons in the conduction band reduce gas-phase oxygen on $\mathrm{GaAs}$ to give $\mathrm{O}^{2-}$ ions while photogenerated holes are transferred from the valence band of GaAs to the As layer, causing oxidation (to $\mathrm{As}^{3+}$ ). In this way $\mathrm{As}_{2} \mathrm{O}_{3}$ would be formed. However, such a mechanism cannot account for the oxide micro-crystals with dimensions much larger than the thickness of the As layer. Transport of products along the surface is required for this.

If some water is present on the surface, as expected in an ambient environment with a relative humidity of about $40-60 \%,{ }^{29}$ then products will be formed in a thin liquid layer during illumination.

$$
\begin{gathered}
\mathrm{As}+2 \mathrm{H}_{2} \mathrm{O}+3 \mathrm{~h}^{+} \rightarrow \mathrm{AsO}_{2}^{-}+4 \mathrm{H}^{+} \\
\mathrm{O}_{2}+2 \mathrm{H}_{2} \mathrm{O}+4 \mathrm{e}^{-} \rightarrow 4 \mathrm{OH}^{-}
\end{gathered}
$$

The $\mathrm{AsO}_{2}{ }^{-}$ions can be transported by convective diffusion. ${ }^{30,31}$ Super-saturation and hydrolysis will cause $\mathrm{As}_{2} \mathrm{O}_{3}$ to precipitate 

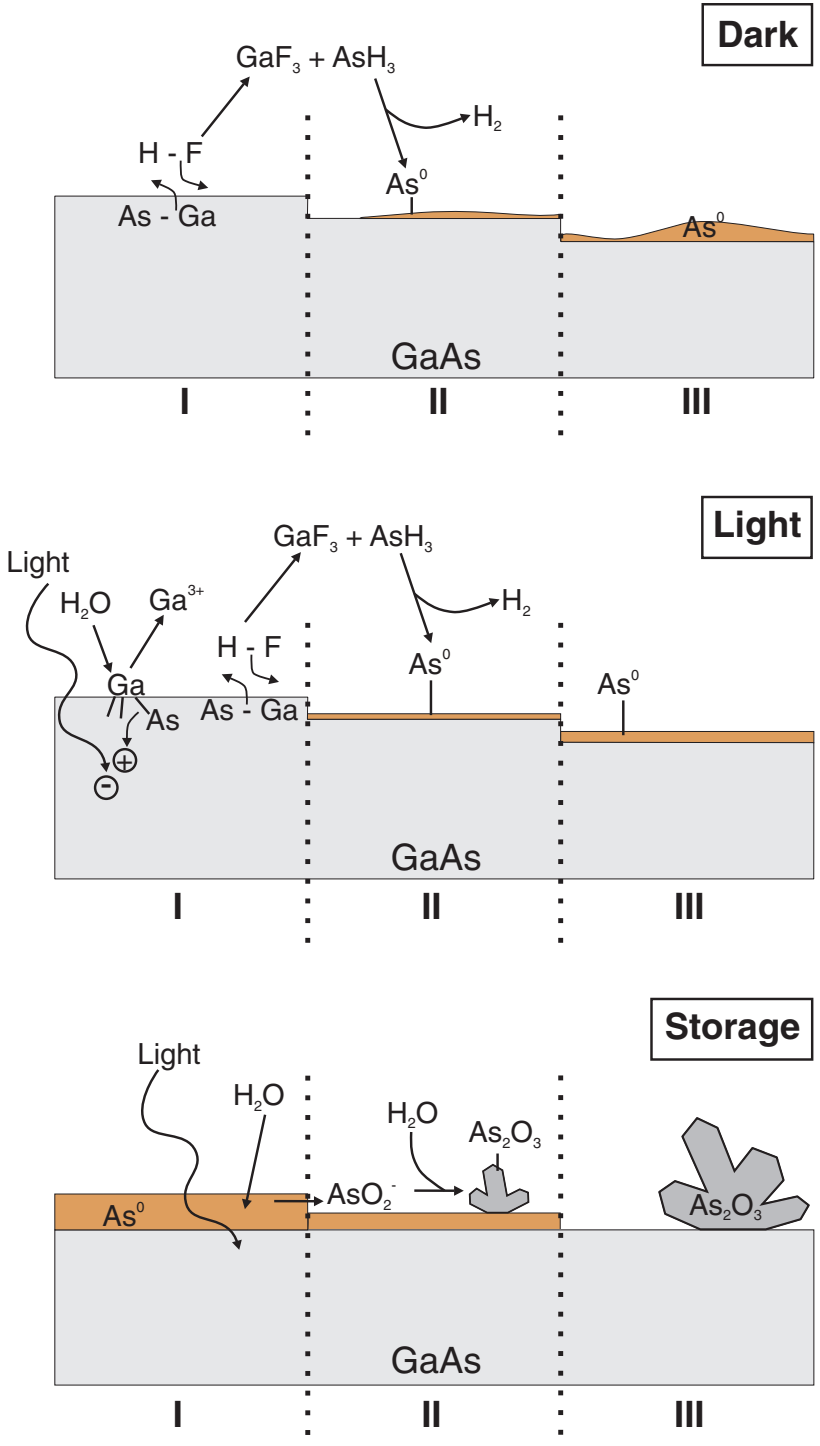

Figure 10. Schematic overview of processes occurring during etching of GaAs in a HF solution in the dark (top), or under illumination (middle), as well as during storage (bottom). With light a second reaction can take place (reaction 3), but since it is expected that this reaction does not influence the As layer formation it is not depicted in the figure.

(preferentially on existing oxide crystallites).

$$
2 \mathrm{AsO}_{2}^{-}+\mathrm{H}_{2} \mathrm{O} \rightarrow \mathrm{As}_{2} \mathrm{O}_{3}+2 \mathrm{OH}^{-}
$$

The As film formed during etching in the dark is non-uniform and its thickness can exceed that of the film formed under illumination. In the latter case the layer thickness depends on the HF concentration. The steady-state thickness of the As film is determined by the rates of its formation and dissolution. As mentioned previously, arsenic is expected to oxidize and dissolve in oxygenated solutions. The results of the photo-oxidation of As in stored samples suggest that light can also play a role in the oxidation of As in solution (similar to reactions 6 and 7). This process must be more favorable than oxidation in the dark to explain the reduced thickness of the film. While oxidation of As in the dark is thermodynamically favorable, the reaction may be kinetically limited.

The dependence of the thickness of the As film on the HF concentration (Figure 4) can be determined by the formation of the film and/or its dissolution. We propose that reaction 4 is responsible for nucleation of the film; this competes with reaction 3 in which both $\mathrm{Ga}$ and $\mathrm{As}$ are oxidized. Since reaction 3 requires $\mathrm{H}_{2} \mathrm{O}$, its rate de- creases as the HF concentration is increased, with polar HF molecules adsorbing and thus preventing access of $\mathrm{H}_{2} \mathrm{O}$ to surface sites. As a result, the nucleation reaction is favored, enhancing film growth in the early stages. Unfortunately it is difficult to test this hypothesis experimentally; the etch rates of these processes are much lower than the rate of the chemical etching (reaction 1). The HF concentration may in a similar way influence removal of the As layer by photostimulated oxidation (reaction 6) which also requires the participation of $\mathrm{H}_{2} \mathrm{O}$ in the surface reaction: an increased HF concentration will lead to a lower As dissolution rate.

The characterization of the contamination on GaAs wafers after ELO helps us to develop a wet-etch procedure to clean the wafers to allow reuse. The current study indicates that there are two options: the wafers can be cleaned immediately after etching (or after storage in the dark and/or vacuum) by removing the elemental As layer. Alternatively, wafers can be stored after etching so that $\mathrm{As}_{2} \mathrm{O}_{3}$ particles form, which can then be removed either by dissolving them or in a brush setup. Further experiments are needed to see which cleaning procedure gives the best results for the reuse of the wafers.

\section{Conclusions}

In order to develop a wet-etch cleaning procedure for wafers after ELO, the contamination that forms during this process was studied. The brown layer that appears on GaAs wafers during etching in an HF solution is demonstrated to consist of elemental As. We suggest there are two mechanisms for the formation of the As. In the dark etching is a chemical reaction resulting in arsine formation, which can then decompose to elemental As. When GaAs is exposed to light electron-hole pairs are formed; the holes are used in an anodic etching reaction resulting in a uniform As layer on the surface; this serves as a nucleation layer for As deposition from arsine. Upon storage of the etched samples the deposited As layer gradually oxidizes and forms $\mathrm{As}_{2} \mathrm{O}_{3}$ micro-crystals.

The characterization of the deposit on GaAs wafers after ELO should enable the development a cleaning procedure that targets either elemental As or $\mathrm{As}_{2} \mathrm{O}_{3}$ particles.

\section{Acknowledgments}

The authors thank W.J.P. van Enckevort for fruitful discussions concerning crystal growth and G.A.M. Kip for performing the XPS measurements. Financial support was provided by the Dutch space organization (NSO) under project number PEP 61727 DS and the Dutch technology foundation (STW) under project number 07452

\section{References}

1. D. J. Friedman, Current Opinion in Solid State \& Materials Science, 14, 131 (2010).

2. M. A. Green, K. Emery, Y. Hishikawa, W. Warta, and E. D. Dunlop, Progress in Photovoltaics, 19, 565 (2011).

3. J. J. Schermer, G. J. Bauhuis, P. Mulder, W. J. Meulemeesters, E. Haverkamp, M. M. A. J. Voncken, and P. K. Larsen, Applied Physics Letters, 76, 2131 (2000).

4. G. J. Bauhuis, P. Mulder, E. J. Haverkamp, J. J. Schermer, L. J. Nash, D. J. F. Fulgoni, I. M. Ballard, and G. Duggan, in Photovoltaic Specialists Conference (PVSC), 2010 35th IEEE, p. 001243 (2010).

5. J. J. Schermer, P. Mulder, G. J. Bauhuis, M. Voncken, J. van Deelen, E. Haverkamp, and P. K. Larsen, Physica Status Solidi a-Applications and Materials Science, 202, 501 (2005).

6. G. J. Bauhuis, P. Mulder, E. J. Haverkamp, J. J. Schermer, E. Bongers, G. Oomen, W. Kostler, and G. Strobl, Progress in Photovoltaics, 18, 155 (2010).

7. G. J. Bauhuis, P. Mulder, E. J. Haverkamp, J. Huijben, and J. J. Schermer, Solar Energy Materials and Solar Cells, 93, 1488 (2009).

8. J. J. Schermer, P. Mulder, G. J. Bauhuis, P. K. Larsen, G. Oomen, and E. Bongers, Progress in Photovoltaics, 13, 587 (2005).

9. M. A. Green, K. Emery, Y. Hishikawa, W. Warta, and E. D. Dunlop, Progress in Photovoltaics, 20, $12(2012)$

10. R. Tatavarti, G. Hillier, G. Martin, A. Wibowo, R. Navaratnarajah, F. Tuminello, D. Hertkorn, M. Disabb, C. Youtsey, D. McCallum, and N. Pan, in Photovoltaic Specialists Conference (PVSC), 2009 34th IEEE, p. 002065 (2009)

11. G. J. Bauhuis, P. Mulder, E. J. Haverkamp, J. J. Schermer, L. J. Nash, D. J. F. Fulgoni, I. M. Ballard, and G. Duggan, AIP Conference Proceedings, 1277, 16 (2010). 
12. B. Furman, E. Menard, A. Gray, M. Meitl, S. Bonafede, D. Kneeburg, K. Ghosal, R. Bukovnik, W. Wagner, J. Gabriel, S. Seel, and S. Burroughs, in Photovoltaic Specialists Conference (PVSC), 201035 th IEEE, p. 000475 (2010).

13. J. Yoon, S. Jo, I. S. Chun, I. Jung, H. S. Kim, M. Meitl, E. Menard, X. L. Li, J. J. Coleman, U. Paik, and J. A. Rogers, Nature, 465, 329 (2010).

14. B. M. Kayes, H. Nie, R. Twist, S. G. Spruytte, F. Reinhardt, I. C. Kizilyalli, and G. S. Higashi, in Photovoltaic Specialists Conference (PVSC), 37th IEEE (2011).

15. A. T. J. van Niftrik, J. J. Schermer, G. J. Bauhuis, P. Mulder, P. K. Larsen, and J. J. Kelly, Journal of the Electrochemical Society, 154, D629 (2007).

16. M. Voncken, J. J. Schermer, A. T. J. van Niftrik, G. J. Bauhuis, P. Mulder, P. K. Larsen, T. P. J. Peters, B. de Bruin, A. Klaassen, and J. J. Kelly, Journal of the Electrochemical Society, 151, G347 (2004).

17. X. S. Wu, L. A. Coldren, and J. L. Merz, Electronics Letters, 21, 558 (1985).

18. M. M. A. J. Voncken, J. J. Schermer, G. J. Bauhuis, P. Mulder, and P. K. Larsen, Applied Physics a-Materials Science \& Processing, 79, 1801 (2004).

19. J. Engel, Substrate degradation upon Epitaxial Lift-Off: an HF etch process study, in, Radboud University Nijmegen, Nijmegen (2011).

20. P. Swift, Surf. Interface Anal., 4, 47 (1982).
21. W. Storm, D. Wolany, F. Schroder, G. Becker, B. Burkhardt, and L. Wiedmann, J. Vac. Sci. Technol. B, 12, 147 (1994).

22. P. H. L. Notten, J. J. Kelly, and J. E. A. M. van den Meerakker, Etching of III-V semiconductors: an electrochemical approach, Elsevier Advanced Technology, Cambridge, UK (1990)

23. P. H. L. Notten, Journal of the Electrochemical Society, 131, 2641 (1984).

24. R. M. Costescu, C. Deneke, D. J. Thurmer, and O. G. Schmidt, Nanoscale Research Letters, 4, 1463 (2009).

25. J. J. Kelly and D. Vanmaekelbergh, in Semiconductor Micromachining: Fundamental electrochemistry and physics, S. A. Campbell and H. J. Lewerenz Editors, Wiley, Chichester (1997).

26. R. Memming and G. Schwandt, Electrochim. Acta, 13, 1299 (1968).

27. E. K. Propst, K. W. Vogt, and P. A. Kohl, Journal of the Electrochemical Society, 140, $3631(1993)$

28. J. J. Kelly, B. P. Minks, N. A. M. Verhaegh, J. Stumper, and L. M. Peter, Electrochim. Acta, 37, 909 (1992).

29. G. E. Ewing, Journal of Physical Chemistry B, 108, 15953 (2004).

30. Q. Dai, J. Hu, and M. Salmeron, Journal of Physical Chemistry B, 101, 1994 (1997).

31. M. C. R. Heijna, M. J. Theelen, W. J. P. van Enckevort, and E. Vlieg, Journal of Physical Chemistry B, 111, 1567 (2007) 